\title{
Students' perceptions of using mobile technologies in informal English learning during the COVID-19 epidemic: A study in Chinese rural secondary schools
}

\author{
Jiayi Guo', Fang Huang'2, Yongqiang Lou ${ }^{3}$ and Shaomei Chen ${ }^{4}$ \\ ${ }^{1}$ School of Foreign Languages, Qingdao University, Qingdao, China (ORCID: 0000-0002-4573-5022) \\ ${ }_{2}^{2}$ School of Foreign Languages, Qingdao University, Qingdao, China (ORCID: 0000-0001-6706-8251) \\ ${ }^{3}$ School of Foreign Languages, Qingdao University, Qingdao, China (ORCID: 0000-0003-2390-1090) \\ ${ }^{4}$ School of Foreign Languages, Qingdao University, Qingdao, China (ORCID: 0000-0001-7936-4111)
}

\begin{abstract}
During the COVID-19 quarantine period, mobile technologies have been greatly promoted to be used by students to assist their learning. Although mobile learning has been well researched, studies investigating rural school students' intentions were not enough. This study investigated rural secondary school students' mobile technology uptake and their perceptions of using mobile technologies in informal English learning during the COVID-19 epidemic. Results suggested Chinese rural school students held positive attitudes towards mobile assisted English learning, and they most tended to use smartphones, followed by portable electronic dictionaries, tablets and laptops in informal English learning. Rural secondary school students' behavioral intentions (BI) were significantly influenced by perceived usefulness (PU), facilitating conditions (FC) and attitude towards use (ATU) of mobile devices. Innovativeness (INNO) and perceived ease of use (PEU) did not significantly influence students' behavioral intentions. These factors explained $83.1 \%$ of variance of students' behavioral intentions. Based on the findings, the study offers suggestions that teachers, governments and educational policy makers take measures to pay attention to students' mobile learning in informal English learning.
\end{abstract}

Keywords: Rural secondary school students; English learning; Mobile Technologies; China

Article History: Submitted 28 August 2020; Revised 29 September 2020; Published online 3 October 2020

\section{Introduction}

Influenced by the COVID-19 epidemic, people in many countries have been quarantined which brought about unexpected inconveniences in many aspects of their life. Schools were closed and governments in many countries issued policies to promote online teaching and learning. For example, the Chinese Ministry of Education issued a notice in early 2020 requiring teachers and students at all educational levels to use long-distance educational technologies to ensure the teaching and learning during the suspension of classes. Among plenty of educational technologies, mobile learning based on mobile devices has been widely utilized by students during this period due to its great advantages of not being limited by time and place (Naciri et al., 2020).

Address of Corresponding Author

Fang Huang, Foreign Languages Education Research Center, School of Foreign Languages, Qingdao University, Ningxia road 308, Shinan District, China.

$\checkmark$ huang311fang@163.com

How to cite: Guo, J., Huang, F., Lou, Y., \& Chen, S. (2020). Students' perceptions of using mobile technologies in informal English learning during the COVID-19 epidemic: A study in Chinese rural secondary schools. Journal of Pedagogical Research, 4(4), 475-483. 
Furthermore, compared with teachers operating computers in formal classroom teaching, this period of online education required students to learn how to operate the technologies by themselves in their homes. Students might change their behavioral intentions to use mobile technologies in online education. Therefore, it is necessary to investigate students' perceptions of using mobile technologies in informal learning during the COVID-19 epidemic.

Because of the mobility and flexible advantages, mobile devices are widely used in language learning (Burston, 2014), such as vocabulary learning (Levy \& Kennedy, 2005) and improving listening skills (Banister, 2010). It can be said that the development of mobile devices (e.g., smartphones, ipads, laptops) make it easier for students to learn languages without carrying heavy books or having to be in the classroom. So, informal English learning environment was selected as the research context in this study.

\subsection{Rationale of the Study}

Despite the policy compulsion and reported advantages that educational technologies bring to learning, students may still have reluctant attitudes towards using mobile learning. This is suggested by existing contradiction in literature. According to Kinash et al. (2012), students were not sure about the benefits that mobile learning brought to them. Dashtestani (2013) found that students were easily distracted by using electronic devices in classes. So, it is still a problem to explore whether students as technology users hold positive attitudes towards mobile learning. In addition, technological and Internet access in many areas may not be good enough to support students' learning. According to Kapasia et al. (2020), students from Indian remote areas and marginalized sections faced enormous challenges for online learning during the COVID-19, because poor economic conditions limited them to have Internet connectivity, and some of them even needed to share equipment with their families or neighbors to attend online classes. Adnan and Anwar (2020) believed that many students in Pakistan cannot access the Internet due to technologies as well as economic limitations. China also faces similar problems, students in Chinese rural areas where family social economic status are generally not compared to those in cities, lack of facilitating conditions such as poor Internet connection and mobile learning tools may constitute great barriers to students' mobile learning intentions ( $\mathrm{Yu}$, Wang \& Che, 2005). Although first-order barriers such as technology access (Ertmer, 1999) are losing their importance in developed countries, they still remain critical for people in underdeveloped rural areas. Therefore, it is necessary to investigate students' perceptions of using mobile technologies in informal English learning during the COVID-19 epidemic in rural areas.

Moreover, students' intentions to use technology could influenced by other internal factors (i.e., beliefs, attitudes) which were categorized as the second-order barriers by Ertmer (1999). These require further research by scholars in various contexts. This study examined students' perceptions of perceived usefulness (PU), perceived ease of use (PEU), attitude towards use (ATU), facilitating conditions (FC) and innovativeness (INNO) to investigate influences on their behavioral intentions (BI) to use mobile teaching technologies during the COVID-19 pandemic. According to Davis (1989), PU and PEU examined the extent to which students believed mobile assisted language learning as useful and free of effort, respectively. ATU indicated the degree of students' favor (like or dislike) regarding mobile technologies in learning. BI suggested the extent to which students would use mobile technologies in learning. Facilitating conditions (FC) measured both access to equipment and technical support when students need (Teo et al., 2018). Innovativeness (INNO) suggested students' willingness to try new technology (Agarwal \& Prasad, 1998). Based on the above, the following hypotheses were formulated.

H1: PU influences BI.

H2: PEU influences BI.

H3: ATU influences BI.

H4: FC influences BI.

H5: INNO influences BI. 
The majority of studies about educational technologies using behavioral intentions took place in formal school settings and very few are conducted in informal settings (Crompton et al., 2017). The COVID-19 epidemic disease made online learning become a necessary and vital learning approach for students. In this situation, students' perceptions of mobile learning may be different because mobile devices were on a large scale applied in the informal context (home) as formal learning tools. In addition, as the systematic review by Crompton et al. (2017) suggested, existing researches on mobile learning are mostly about elementary school students' science subject study, with a focus on secondary school students' mobile assisted language learning are still lacking. Therefore, this study focused on secondary school students' behavioral intentions of using mobile technologies in informal English learning during the COVID-19 epidemic.

\subsection{Purpose and Significance of this Study}

Based on the rationale of the study, the current study aimed to examine rural school students' perceptions of mobile learning during the COVID-19 epidemic in the informal English learning context. The research questions were: (1) What mobile devices did rural secondary school students adopt in English learning during the COVID-19 epidemic? (2) What factors influence their perceptions of mobile assisted English learning in the informal learning context?

This study contributed to mobile-assisted language learning theories by unpacking rural secondary school students' intentions to use mobile technologies in English learning during the COVID-19 isolating period. It can offer empirical evidence and data support for teachers, educational administrators and governments to take measures to students' mobile learning in informal English learning.

\section{Method}

\subsection{Research Design}

This study used quantitative research design to explore rural school students' perceptions of mobile assisted language learning during the COVID-19 epidemic in China. Quantitative research can explain certain specific phenomena by collecting numerical data that is analyzed by using mathematical methods (Aliaga \& Gunderson, 2002). This method is concerned with the development and testing of hypotheses and the generation of models and theories that explain behavior (Hoy \& Adams, 2015). Research questionnaires were designed and distributed to participants through an online survey tool provided by WeChat.

Collected data was analyzed by using the SPSS 24.0. Descriptive analyses were applied to suggest students' demographic information, using experience of mobile devices, as well as their perceptions of mobile assisted English learning. The following introduced details of participants, procedures, and questionnaire in the study.

\subsection{Participants}

Participants in the current study were 208 secondary school students from 4 middle schools and 3 high schools in Liangshan, a small under-developed county which is located on the border of Henan Province and Shandong Province in China. Agriculture and animal husbandry are important industries in this county. Among the 208 students, 194 reported their age and the mean age was $15.04(\mathrm{SD}=2.266)$, ranging from 14 to 20 years old. $63.9 \%$ of them $(\mathrm{N}=133)$ are junior middle school students and $36.1 \%$ of them $(\mathrm{N}=75)$ are now in the senior middle school stage (high schools). Among the participants, there are 44 boys (accounting for 21.2\%) and 164 girls (accounting for $78.8 \%$ ).

This study used $G^{*}$ power 3.1 to determine the minimum sample size. Each group sample size is 64 , which is calculated by the required power level $(1-\beta) 0.8$, and the prespecified significance level a 0.05 . The number of participants in middle schools and high schools in this study was more than 64, which ensured the feasibility of the study. 


\subsection{Procedure}

At the beginning of 2020, the authors distributed online questionnaires using WeChat, an online survey tool in China, to the participants with the help of our contacts in seven rural secondary schools in China. Students were informed of the voluntariness of participating in the study, and their responses to the survey items would be anonymous and used only for research purpose. Given the convenience sampling technique used in data collection, students were from Liangshan County and its affiliated villages in China.

\subsection{Materials}

The questionnaire used in this study is titled "A Survey of Rural School students' Use of Mobile Devices in English Learning during the Outbreak". And the questionnaire consists of two parts. In the first part, there are questions requiring students' demographic information, such as age, gender, school grades, technological tools they use and frequencies of using. In the second part, questions relating to students' perceptions of using these tools in English learning are included in the questionnaire. And this part consists of six constructs, including perceived usefulness (PU) (8 items), perceived ease of use (PEU, 5 items), attitude towards use (ATU, 6 items), intentions to use mobile assisted language learning (BI, 4 items), facilitating conditions (FC, 5 items) and innovativeness (INNO, 6 items). All of the constructs were adapted from published literature (see in Table 1) and were found to be reliable and valid. The reliabilities of these constructs achieved satisfactory level given the Cronbach's alphas were all above .9. Henson (2001) believed that the value of Cronbach's alphas exceeds .80 that can be considered a generally accepted standard. These constructs were tested by using a seven-point Likert scale $(1=$ strongly disagree, 7 = strongly agree), given that a seven-point Likert scale has optimal reliability (Symonds, 1924).

Table 1 illustrated detailed information of the survey, including number of items, sources and reliabilities.

Table 1

Questionnaire Source and Reliability

\begin{tabular}{lccc}
\hline Constructs & $\begin{array}{c}\text { Number of } \\
\text { items }\end{array}$ & Source & $\begin{array}{c}\text { Cronbach's } \\
\text { Alpha }\end{array}$ \\
\hline Perceived Usefulness (PU) & 8 & Teo et al. 2018 & 0.932 \\
Perceived Ease of Use (PEU) & 5 & Teo et al. 2018 & 0.917 \\
Attitude Towards Use (ATU) & 6 & Teo et al. 2018 & 0.942 \\
Behavior Intention (BI) & 4 & Teo et al. 2018 & 0.936 \\
Facilitating Conditions (FC) & 5 & Teo et al. 2018 & 0.906 \\
Innovativeness (INNO) & 6 & Khlaisang et al. 2019 & 0.911 \\
\hline
\end{tabular}

\section{Results}

\subsection{Descriptive Analysis}

As for the types of mobile devices they used in learning English, smartphones, laptops, tablets as well as portable electronic dictionaries were suggested by students (Table 2). Students reported that they use mobile devices every day and hours of using these devices ranged from 1 to 4 hours, with the mean being 1.99 hours $(\mathrm{SD}=.887)$. Table 2 showed students' self-reported usage behaviors of mobile devices in learning English in the informal context. The frequencies of usage mobile devices were measured in the 5-point scale (1= "Always", 2 = "Often", 3 = "Sometimes", $4=$ "Seldom", $5=$ "Never"). When looking at devices that were used frequently (the sum of numbers of "Always" and "Often"), we could conclude that students most tended to use smartphones (99), followed by portable electronic dictionaries (48), tablets (38) and laptops (34).

As for students' perceptions of mobile assisted English learning in the informal learning context, we have tested students' perceptions of perceived usefulness (PU), perceived ease of use 
(PEU), attitudes (ATU), intentions (BI), facilitating conditions (FC) and innovativeness (INNO), using a 7 -point Likert scale $(1=$ strongly disagree, $7=$ strongly agree). The means and reliabilities of these constructs were presented in Table 3. The data suggested normal distribution as the skewness and kurtosis were within the $|3|$ and $|8|$ suggested by Kline (2010). Students had positive perceptions of mobile assisted English learning as the mean values were all above average level (from 4.86 to 5.27 ).

Table 2

Mobile devices using frequencies $(N=208)$

\begin{tabular}{lccccc}
\hline Mobile devices & Always & Often & Sometimes & Seldom & Never \\
\hline Smartphone & 51 & 48 & 81 & 19 & 9 \\
Laptop & 15 & 19 & 51 & 46 & 77 \\
Tablet & 21 & 17 & 47 & 52 & 71 \\
Electronic dictionary & 19 & 29 & 56 & 40 & 64 \\
\hline
\end{tabular}

Table 3

Descriptions of constructs $(N=208)$

\begin{tabular}{lccccc}
\hline & Number of items & Mean & SD & Skewness & Kurtosis \\
\hline PU & 8 & 5.21 & 1.03 & 0.38 & -0.44 \\
PEU & 5 & 5.05 & 1.14 & 0.22 & -0.05 \\
ATU & 6 & 5.01 & 1.14 & 0.26 & -0.25 \\
BI & 4 & 5.03 & 1.14 & 0.38 & -0.40 \\
FC & 5 & 5.27 & 1.07 & 0.25 & -0.48 \\
INNO & 6 & 4.86 & 1.06 & 0.79 & -0.19 \\
\hline
\end{tabular}

Note: PU: perceived usefulness, PEU: perceived ease of use, ATU: attitude towards use, BI: behavioral intentions, FC: facilitating conditions, INNO: innovativeness.

\subsection{Regression Analysis}

Table 4 indicated the variables in the study having well correlated. We further examined the extent to which the independent variables (PU, PEU, ATU, INNO, FC) predicted rural students' intentions to use mobile technologies in English learning (BI as the dependent variable). The correlation coefficients ranged from .653 to .901. It can be said that there were significant relationships among these constructs.

In this study, the regression model was generated to investigate students' perceptions of using mobile technologies in informal English learning during the COVID-19 epidemic. As Table 5 indicated, the independent variables explained $83.1 \%$ of the variance of BI. Among the independent variables, PU, ATU, and FC significantly influenced students' behavioral intentions, with standardized regression coefficients being .123, .646, and .093 respectively (Table 6). Therefore, H1, H3 and H4 were supported.

Table 4

Correlations of constructs

\begin{tabular}{lllllll}
\hline & PU & PEU & ATU & BI & INNO & FC \\
\hline PU & 1 & & & & & \\
PEU & $.854^{* *}$ & 1 & & & & \\
ATU & $.835^{* *}$ & $.864^{* *}$ & 1 & & & \\
BI & $.808^{* *}$ & $.820^{* *}$ & $.901^{* *}$ & 1 & & \\
INNO & $.658^{* *}$ & $.723^{* *}$ & $.743^{* *}$ & $.742^{* *}$ & 1 & $.732^{* *}$ \\
FC & $.677^{* *}$ & $.691^{* *}$ & $.653^{* *}$ & $.684^{* *}$ & 1 \\
\hline
\end{tabular}

Note: ${ }^{* *}$. Correlation is significant at the 0.01 level (2-tailed). PU: perceived usefulness, PEU: perceived ease of use, ATU: attitude towards use, BI: behavioral intentions, INNO: innovativeness, FC: facilitating conditions. 
Table 5

Model summary

\begin{tabular}{lllll}
\hline Model & R & R Square & Adjusted R Square & Std. Error of the Estimate \\
\hline 1 & $.914^{\mathrm{a}}$ & 0.835 & 0.831 & 0.46771 \\
\hline
\end{tabular}

Table 6

Results of regression model

\begin{tabular}{llllll}
\hline Model & \multicolumn{2}{l}{ Unstandardized Coefficients } & $\begin{array}{l}\text { Standardized } \\
\text { Coefficients } \\
\text { Beta }\end{array}$ & t & Sig. \\
\hline (Constant) & -0.049 & 0.183 & & -0.265 & 0.792 \\
PU & 0.136 & 0.067 & $0.123^{*}$ & 2.028 & 0.044 \\
PEU & 0.023 & 0.067 & 0.023 & 0.345 & 0.730 \\
ATU & 0.645 & 0.065 & $0.646^{* * *}$ & 9.969 & 0.000 \\
FC & 0.099 & 0.049 & $0.093^{*}$ & 2.031 & 0.044 \\
INNO & 0.103 & 0.053 & 0.096 & 1.940 & 0.054 \\
\hline
\end{tabular}

Note: Dependent Variable: BI. ${ }^{*} p<0.05,{ }^{* * *} p<0.001$. PU: perceived usefulness, PEU: perceived ease of use, ATU: attitude towards use, BI: behavioral intentions, FC: facilitating conditions, INNO: innovativeness.

\section{Discussion}

This study examined rural school students' mobile technology usage and their perceptions of mobile learning during the COVID-19 epidemic in the informal English learning context. The results suggested that rural students generally used smartphones, laptops, tablets and electronic dictionaries to assist their English learning during the COVID-19. They had very positive attitudes towards mobile assisted English learning and they use mobile devices every day. This finding was consistent with other studies among students regarding their mobile learning (e.g., Barhoumi, 2015; Park, Nam, \& Cha, 2012). The main reason is that today's secondary school students are digital natives (Prensky, 2001) who grew up with digital media and have been living in a digital environment since they were born. They spent a great deal of time using mobile devices and they are truly native speakers of the digital language (Prensky, 2001). Therefore, secondary students have positive attitudes to mobile devices by nature. Through self-reported data, students suggested they had good facilitating conditions including access to equipment and technical support $(M=5.27)$. China Internet Network Information Center (2020) reported that the Internet penetration rate in Chinese rural areas was 46.2 percent, indicating that infrastructure construction in rural areas, to a certain degree, meet students' needs to attend online classes during the COVID19. Also, given the Chinese government concerned the imbalanced regional development in China, they tried to provide satellite TV for remote and rural families who have poor Internet access to ensure students' online learning (Zhang, Wang, \& Yang, 2020). But it was worth noting that facilitating conditions consist of technology facilities as well as technical support (Groves \& Zemel, 2000). During the COVID-19, some Chinese schools also invited online teaching technology consultants to assist teachers and students to solve problems during online education. Therefore, students believed that they had good facilitating conditions to learn at home. In addition, students believed mobile assisted language learning was very useful during the epidemic period $(\mathrm{M}=5.21)$ and these technologies were easy to use $(M=5.05)$. They liked to use mobile technologies in learning English $(\mathrm{M}=5.01)$, and they perceive themselves as kind of innovative in dealing with technologies $(\mathrm{M}=4.86)$.

This study used six factors including perceived usefulness (PU), perceived ease of use (PEU), attitude towards use (ATU), behavioral intentions (BI), facilitating conditions (FC), and innovativeness (INNO) to predict rural students' perceptions to use mobile technologies in English learning, with the total variance explained being $83.1 \%$. Among all 5 hypotheses, 3 of them were supported (H1, H3 and $\mathrm{H} 4)$, while 2 of them were not (H2 and $\mathrm{H} 5)$. PU, ATU, and FC were 
significant factors predicted rural students' intentions, this was in line with the technology acceptance model (Davis, 1989) and previous studies (Huang \& Teo, 2020). Teo (2009) believed that users are more likely to use technology when the technology is perceived to be useful, and this positive attitude can directly influence their behavior intentions to use technologies. So, PU and ATU had significant influence on students' intentions to use mobile technologies in informal English learning. FC had significant influence on students' behavior intentions. This result was consistent with Thomas et al. (2013). Facilitating conditions were first-order barriers for secondary students to accept online education in the informal learning environment. Because compared with facilities in classrooms offered by the governments, quality of technology tools and network speed were still important factors for rural students to adopt online education at their homes. Thomas et al. (2013) also believed that whenever there are constraints on technology resources, facilitating conditions would become an important predictor of behavioral intention.

However, the influence of perceived ease of use (PEU) did not achieve the significant level, suggesting students would not consider effortlessness as important factors when thinking about using mobile technologies in learning. This was in line with Teo et al. (2018) study in which Chinese teachers were suggested as diligent and dedicated to teaching so that they would not accept technologies just because of its effortlessness. In this study, the participants were secondary students who are digital nativities. They grew up and were familiar with mobile devices and thus, were not really bothered to make efforts in using mobile devices (Prensky, 2001). Therefore, PEU had no significant influence on BI. Innovativeness was suggested to influence attitudes (Khlaisanga, Teo, \& Huang, 2019) but did not significantly influence rural students' mobile learning behavioral intentions in this study. Innovativeness refers to the willingness of an individual to try new technologies. However, the most important thing for students in online education was listening to teachers by using mobile devices, and there were few opportunities for them to explore new technologies in study by themselves. So, INNO had no significant influence on BI.

\subsection{Limitations}

This study also had some limitations. First, considering the large population of Chinese rural citizens, the sample size was comparatively small, and it cannot represent all Chinese rural secondary school students. Further studies were suggested to expand the sample size to get a full picture of rural students' technology used in informal English learning. Second, due to the impact of the COVID-19 epidemic, this study adopted online questionnaires to investigate students' perceptions of using mobile technologies in informal English learning. Compared with the lack of participation willingness in online questionnaires, traditional paper-and-pencil surveys may provide higher response rates (Lefever et al., 2007). Third, other factors that might influence students' intentions to use mobile technologies in learning English during the COVID-19, such as subjective norm (Teo, 2012) and self-efficacy (Yang, 2012), were not tested. Future studies can add these factors in the research to further explore students' behavioral intentions to use mobile devices in informal English learning.

\section{Conclusion and Suggestions}

The results of this study contributed to mobile-assisted language learning theories by unpacking rural secondary school students' intentions to use mobile technologies in English learning during the COVID-19 isolating period. This study found that Chinese rural school students held positive attitudes towards mobile assisted English learning, and they mostly tended to use smartphones, followed by portable electronic dictionaries, tablets and laptops. Rural secondary school students' intentions were significantly influenced by perceived usefulness (PU), facilitating conditions (FC) and attitude towards the use (ATU) of mobile devices. Innovativeness (INNO) and perceived ease of use (PEU) did not significantly influence students' intentions. These results had important implications for English teaching and learning, as well as teachers, educational administrators and 
policy makers. FC had significant influence on BI, indicating that Chinese governments should continue to increase investment in network infrastructure in rural areas. PU and ATU had significant influence on $\mathrm{BI}$, indicating that teachers can provide more opportunities for students to experience the usefulness of mobile technologies in English learning and improve their attitudes so that they would be more willing to use mobile technologies to improve learning efficiency. Educational administrators in local governments were suggested to design training classes for both teachers and students to improve technology skills to ensure technology integration in teaching and learning.

\section{Acknowledgement}

This research is funded by the 2020 Qingdao Social Science and Planning Research Project (QDSKL2001107): Urban and rural foreign language teachers' informational teaching ability and improvement during and post epidemic period.

\section{References}

Agarwal, R., \& Prasad, J. (1998). A conceptual and operational definition of personal innovativeness in the domain of information technology. Information Systems Research, 9(2), 204-215.

Aliaga, M., \& Gunderson, B. (2002). Interactive statistics. Virginia: Pearson Education.

Adnan, M., \& Anwar, K. (2020). Online learning amid the COVID-19 pandemic: Students' perspectives. Journal of Pedagogical Sociology and Psychology, 2(1), 45-51.

Banister, S. (2010). Integrating the iPod touch in K-12 education: Visions and vices. Computers in the Schools, 27(2), 121-131.

Burston, J. (2014). MALL: The pedagogical challenges. Computer Assisted Language Learning, 27(4), 344-357.

Barhoumi, C. (2015). The effectiveness of Whats app mobile learning activities guided by activity theory on students' knowledge management. Contemporary Educational Technology, 6(3), 221-238.

Crompton, H., Burke, D., \& Gregory, K. H. (2017). The use of mobile learning in PK-12 education: A ystematic review. Computers \& Education, 110, 51-63.

China Internet Network Information Center. (2020). The $45^{\text {th }}$ China statistical report on internet development. Retrieved September 20, 2020, from http://www.cnnic.net.cn/hlwfzyj/hlwxzbg/hlwtjbg/ 202004/P020200428596599037028.pdf

Davis, F. D. (1989). Perceived usefulness, perceived ease of use, and user acceptance of information technology. MIS Quarterly, 13(3), 319-340.

Dashtestani, R. (2013). EFL teachers' and students' perspectives on the use of electronic dictionaries for learning English. CALL-EJ, 14(2), 51-65.

Ertmer, P. A. (1999). Addressing first-and second-order barriers to change: Strategies for technology integration. Educational Technology Research and Development, 47(4), 47-61.

Groves, M. M., \& Zemel, P. C. (2000). Instructional technology adoption in higher education: An action research case study. International Journal of Instructional Media, 27(1), 57-65.

Henson, R. K. (2001). Understanding internal consistency reliability estimates: A conceptual primer on coefficient alpha. Measurement and Evaluation in Counseling and Development, 34, 177-189.

Hoy, W. K., \& Adams, C. M. (2015). Quantitative research in education: A primer. New York: Sage Publications.

Huang, F. \& Teo, T. (2020). Influence of teacher-perceived organisational culture and school policy on chinese teachers' intention to use technology: An extension of technology acceptance model. Educational Technology Research \& Development, 68, 1547-1567.

Kline, R. B. (2010). Principles and practice of structural equation modeling (3rd ed.). New York, NY: Guilford Press.

Kinash, S., Brand, J., \& Mathew, T. (2012). Challenging mobile learning discourse through research: Student perceptions of blackboard mobile learn and iPads. Australasian Journal of Educational Technology, 28(4), 639-655.

Khlaisang, J., Teo, T., \& Huang, F. (2019). Acceptance of a flipped smart application for learning: a study among Thai university students. Interactive Learning Environments, 1-18. 
Kapasia, N., Paul, P., Roy, A., Saha, J., Zaveri, A., Mallick, R., ... \& Chouhan, P. (2020). Impact of lockdown on learning status of undergraduate and postgraduate students during COVID-19 pandemic in West Bengal, India. Children and Youth Services Review, 116, 105194.

Levy, M., \& Kennedy, C. (2005). Learning Italian via mobile SMS. In A. Kukulska-Hulme, J. Traxler (Eds.) Mobile learning: A handbook for educators and trainers (pp. 76-83). London: Taylor \& Francis.

Lefever, S., Dal, M., \& Matthiasdottir, A. (2007). Online data collection in academic research: Advantages and limitations. British Journal of Educational Technology, 38(4), 574-582.

Naciri, A., Baba, M. A., Achbani, A., \& Kharbach, A. (2020). Mobile learning in higher education: Unavoidable alternative during COVID-19. Aquademia, 4(1), ep20016.

Prensky, M. (2001). Digital natives, digital immigrants part 1. On the horizon, 9(5), 1-6.

Park, S. Y., Nam, M. W., \& Cha, S. B. (2012). University students' behavioral intention to use mobile learning: Evaluating the technology acceptance model. British journal of educational technology, 43(4), 592605.

Symonds, P. M. (1924). On the loss of reliability in ratings due to coarseness of the scale. Journal of Experimental Psychology, 7, 456-461.

Teo, T. (2009). Modelling technology acceptance in education: A study of pre-service teachers. Computers $\mathcal{E}$ Education, 52(2), 302-312.

Teo, T. (2012). Examining the intention to use technology among pre-service teachers: An integration of the technology acceptance model and theory of planned behavior. Interactive Learning Environments, 20(1), 318.

Teo, T., Huang, F., \& Hoi, C. K. W. (2018). Explicating the influences that explain intention to use technology among English teachers in China. Interactive Learning Environments, 26(4), 460-475.

Thomas, T. D., Singh, L., \& Gaffar, K. (2013). The Utility of the UTAUT model in explaining mobile learning adoption in higher education in Guyana. International Journal of Education and Development using Information and Communication Technology, 9(3), 71-87.

Yu, S., Wang, M., \& Che, H. (2005). An exposition of the crucial issues in China's educational informatization. Educational Technology Research and Development, 53(4), 88-101.

Yang, S. H. (2012). Exploring college students' attitudes and self-efficacy of mobile learning. Turkish Online Journal of Educational Technology-TOJET, 11(4), 148-154.

Zhang, W., Wang, Y., Yang, L., \& Wang, C. (2020). Suspending Classes Without Stopping Learning: China's Education Emergency Management Policy in the COVID-19 Outbreak. Journal of Risk and Financial Management, 13(3), 1-6. 